\title{
A retrospective descriptive study of cranioplasty failure rates and contributing factors in novel 3D printed calcium phosphate implants compared to traditional materials
}

\author{
Michael Koller ${ }^{1 *}$ (D), Daniel Rafter ${ }^{1,2}$, Gillian Shok ${ }^{1}$, Sean Murphy', Sheena Kiaei ${ }^{1}$ and Uzma Samadani ${ }^{1,2}$
}

\begin{abstract}
Background: Failure rates with cranioplasty procedures have driven efforts to improve graft material and reduce reoperation. One promising allograft source is a 3D-printed titanium mesh with calcium phosphate filler. This study evaluated failure rates and pertinent characteristics of these novel 3D-grafts compared to traditional materials.

Methods: Sixty patients were retrospectively identified who underwent a cranioplasty between January 2015December 2017. Specific data points related to graft failure were collected for all surgical admissions, from the primary injury to their most recent. These included, but were not limited to, initial physical exam findings, vitals, comorbid conditions, surgery length, estimated blood loss, incision type, and need for revision. Failure rates of 3D-printed allografts were compared to traditional grafts.

Results: A total of 60 subjects were identified who underwent 71 unique cranioplasty procedures $(3 \mathrm{D}=13$, Synthetic $=12$, Autologous $=46$ ). There were 14 total failures, demonstrating a $19.7 \%$ overall failure rate. Specifically, $15.4 \%(n=2)$ of 3D, $19.6 \%(n=9)$ of autologous, and $25.0 \%(n=3)$ of synthetic grafts required revision. Patients receiving 3D-grafts had the shortest overall mean surgery times (200.8 $\pm 54.3 \mathrm{~min}$ ) and lowest infection rates $(7.7 \%)$ compared to autologous $(210.5 \pm 47.9 \mathrm{~min} \mid 25.0 \%)$ and synthetic models (217.6 \pm 77.3 $\min \mid 8.7 \%)$, though significance was unable to be determined. Tobacco use and trap-door incisions were associated with increased failure rates relative to straight or curved incisions in autologous grafts.

Cranioplasties performed less than 3 months after craniectomy appeared to fail more often than those performed at least three months after craniectomy, for the synthetic group.

Conclusion: We concluded that 3D-printed cranioplasty grafts may lead to lower failure rates and shorter surgery times compared to traditional cranioplasty materials in our limited population. 3D-implants hold promise for cranial reconstruction after TBI.
\end{abstract}

Keywords: 3D-printed, Cranioplasty, Cranial implant, Craniectomy, Traumatic brain injury

\footnotetext{
*Correspondence: kolle153@umn.edu

'Department of Bioinformatics and Computational Biology, University of Minnesota, 101 Pleasant Street Southeast, Minneapolis, MN 55455, USA

Full list of author information is available at the end of the article
}

(c) The Author(s). 2020 Open Access This article is licensed under a Creative Commons Attribution 4.0 International License, which permits use, sharing, adaptation, distribution and reproduction in any medium or format, as long as you give appropriate credit to the original author(s) and the source, provide a link to the Creative Commons licence, and indicate if changes were made. The images or other third party material in this article are included in the article's Creative Commons. licence, unless indicated otherwise in a credit line to the material. If material is not included in the article's Creative Commons licence and your intended use is not permitted by statutory regulation or exceeds the permitted use, you will need to obtain permission directly from the copyright holder. To view a copy of this licence, visit http://creativecommons.org/licenses/by/4.0/. The Creative Commons Public Domain Dedication waiver (http://creativecommons.org/publicdomain/zero/1.0/) applies to the data made available in this article, unless otherwise stated in a credit line to the data. 


\section{Background}

Decompressive craniectomy (DC) is a common neurosurgical intervention in which a large section of the skull is removed in the setting of severe traumatic brain injury (TBI). The resulting skull defect is left open to allow brain tissue to swell past this rigid border, thus mitigating potentially fatal elevations in intracranial pressure [1-3]. Once the underlying pathology has been corrected, the contour of the skull is reconstructed either with the autologous bone flap or a synthetic implant via cranioplasty. This is done for cosmesis as well as to reduce complications from DC including seizure, posttraumatic hydrocephalus, and syndrome of trephined [4-7]. While cranioplasty is a routine and technically straightforward procedure, current data demonstrates failure and complication rates as high as $40 \%$ due to infection, hardware exposure, and autologous bone resorption [8-10]. As such, there has been a focus on shorter operating times, optimizing time between craniectomy and cranioplasty, and managing patient comorbidities to improve outcomes [11-13].

Another avenue that has been explored is the advancement in cranioplasty material and design. Traditionally, frozen or subcutaneously preserved autologous bone flaps have been used for reconstruction due to lower costs and anatomical fit [14, 15] (Fig. 1). However, current complication rates with this material, specifically bone resorption and infection, have highlighted the role for synthetic alternatives [16-21]. Currently, titanium mesh, polyetheretherketone (PEEK), polymethylmethacrylate (PMMA), and hydroxyapatite implants are being utilized. While each have their own added benefits, they also carry their own unique issues. Titanium mesh possesses noninflammatory and noncorrosive functionality while maintaining strength and malleability, yet creates imaging artifacts and carries an increased risk for metal hypersensitivity leading to device exposure [22-24]. PEEK demonstrates reduced complication and failure rates compared to autologous and titanium counterparts in limited studies [24, 25]. However, PEEK may not always incorporate with the native bone defect, leading to extrusion [23, 26]. PMMA implants have robust compression, heat and stress resistance, and strong adherence [23, 27], but have demonstrated greater infection rates and the potential for exothermic burn reaction due to a polymerization process $[28,29]$. Lastly, hydroxyapatite is known for its contour ability and its excellent cosmesis, but lacks tensile strength and osseointegration, leaving the skull susceptible to fragmentation and infection [30-32]. Overall, synthetic implants have shown lower infection rates and absorption rates compared to autologous $[23,33,34]$. Yet, there are still issues to be addressed with these materials to maximize patient outcome.

A novel implant type, 3D-printed calcium phosphate cement mosaic tiles on a titanium mesh, has recently received Food and Drug Administration approval in the United States [35]. Along with its antimicrobial and osteogenic qualities, these 3D implants are also designed to minimize operation times and optimize cranial defect repair through individualized design (Fig. 2). Due to their recent emergence in the field, there has been
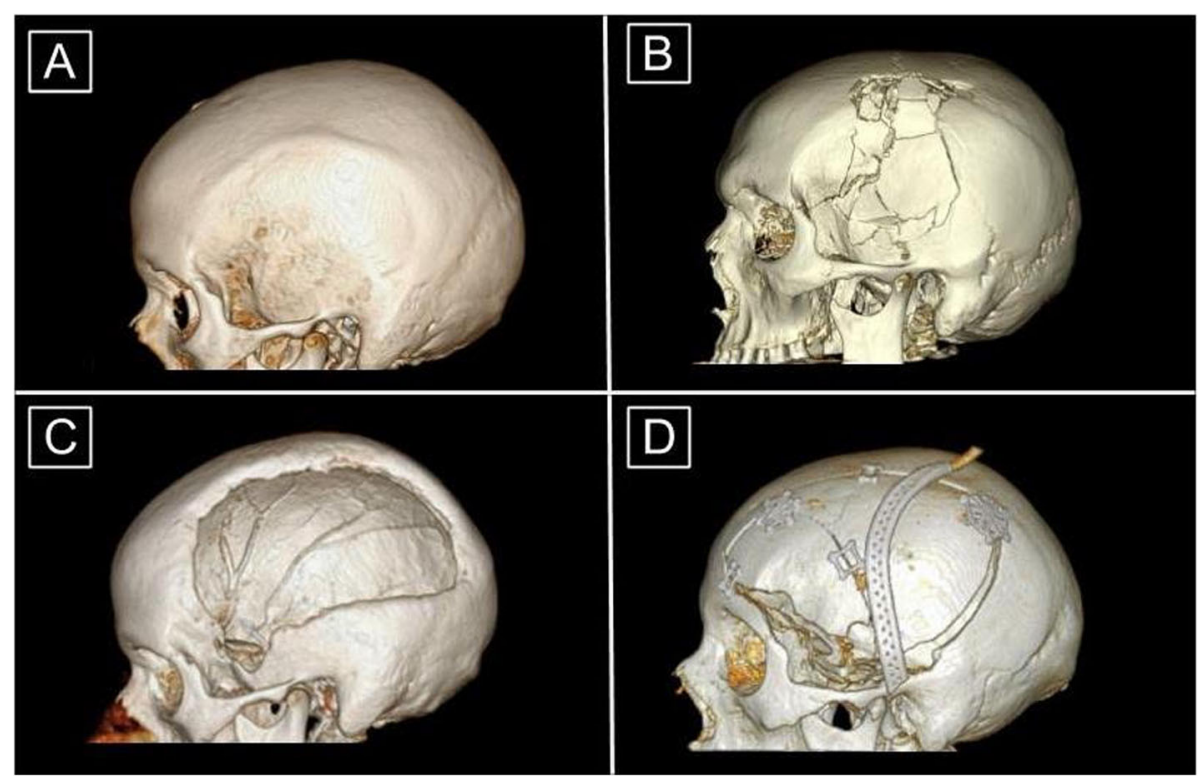

Fig. 1 3D Reconstructions of Head CT Images in Craniectomy and Cranioplasty (a) Intact or normal skull. (b) Skull fracture that is overlying intracranial pathology requiring craniectomy. (c) Cranial defect after craniectomy. Note the asymmetric and heterogeneous nature of the outer border. (d) Post-operative subject who had undergone cranioplasty with autologous bone. The perforated piece overlying the skull is a JacksonPratt drain. Note that the bone fragments require extra structural support and do not fully repair the cranial defect along the inferior border 


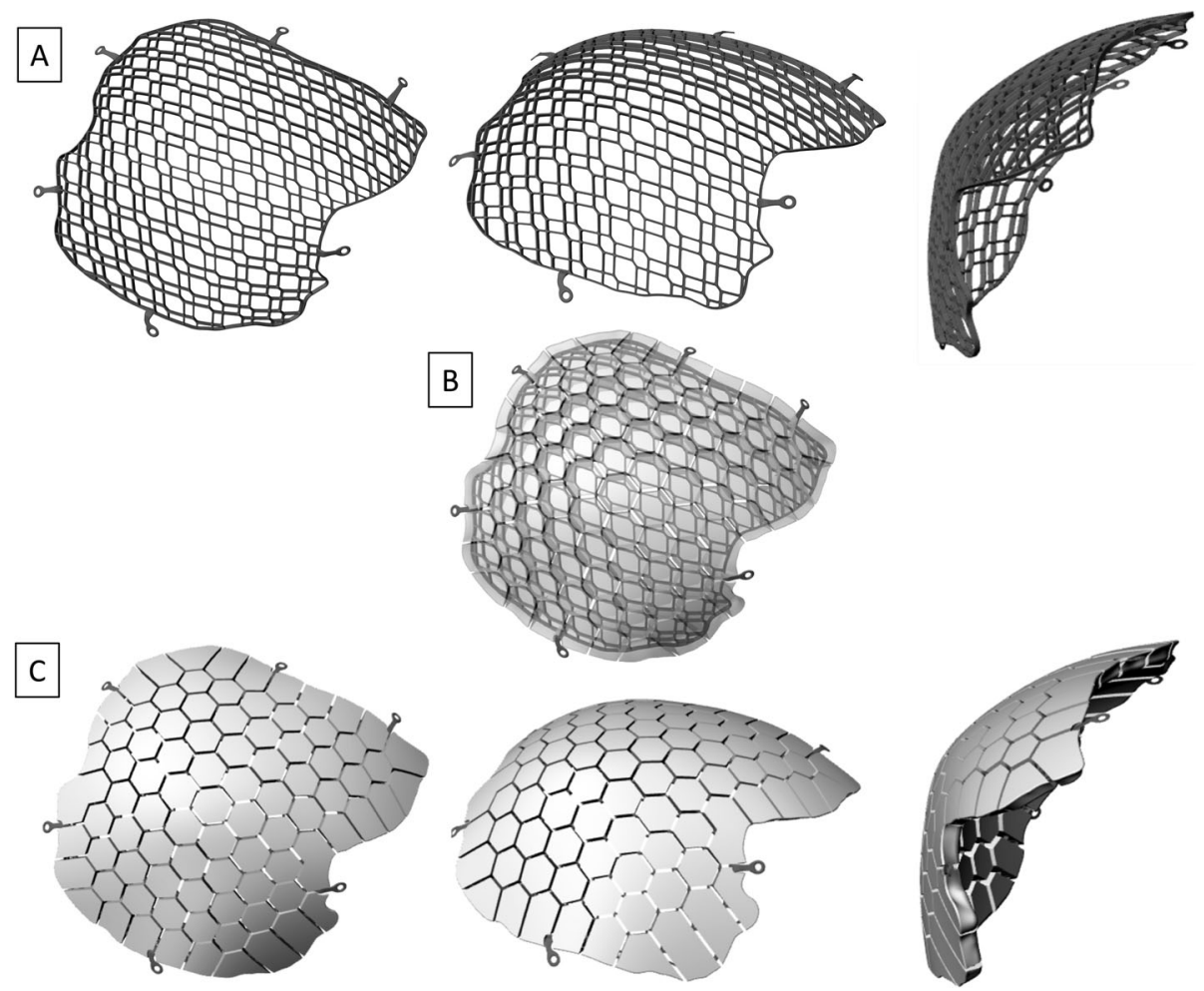

Fig. 2 Images of 3D Printed Titanium Mesh Implants (a) Three views of the 3D printed titanium skeleton. (b) Transparent view of the 3D printed titanium skeleton embedded in the core of the calcium phosphate tiles. (c) Three views of the biocompatible calcium phosphate ceramic tiles situated upon the titanium skeleton layer. Note the mosaic tile design incorporating inter-tile spacing to permit fluid movement throughout the implant to enhance revascularization

limited data published on the failure rates of these 3D implants. One recently published study looked at the outcomes of 50 Swedish patients with the 3D implant, $32(64 \%)$ of whom had a prior failure with autologous or alloplastic implants and subsequently received the 3D implant [35]. Overall, they demonstrated a 7.5\% explantation rate for the 3D implants, as well as in situ bone regeneration and osseointegration [36]. While these findings suggest a significant reduction in cranioplasty failure rates with 3D implants, the study did not investigate or compare the raw failure rates of cohorts receiving different cranioplasty types, and rather only focused on those who received a 3D implant. It also did not directly explore the statistical mediators or complexities between patient cohorts who receive different cranioplasty implant type.

In the present study, we evaluated cranioplasty procedures performed at a level-1 trauma hospital in the United States, specifically focusing on the unique factors with the potential to affect outcomes in 3D-printed grafts, autologous grafts, and other synthetic allografts cohorts. We attempt to better describe the pertinent features of cranioplasty failure at an urban trauma center by capturing patient comorbidities, risk factors, and surgical considerations and contribute to the literature evaluating cranioplasty material.

\section{Materials and methods}

\section{Subject selection and study population}

A retrospective chart review was performed on all patients that underwent cranioplasty from January 1st, 2015 to December 31st, 2017 at our level-1 Trauma Center, Hennepin County Medical Center in Minneapolis, Minnesota. Those included in the study were patients with a prior craniectomy followed by at least one cranioplasty procedure within the aforementioned time interval. Those with insufficient cranioplasty data or documentation, cranioplasty performed at another hospital, and absence of prior craniectomy information were excluded. The study was approved by and conducted in full compliance with the Hennepin Healthcare Research Institute Institutional Review Board with number HSR\#17-4309.

\section{Clinical data}

Clinical data from the electronic medical records (EMR) was retrospectively collected for all patients that had undergone a cranioplasty procedure within the specified time interval, based on relevant ICD-9 and ICD-10 
codes. Data was collected for each surgical admission including the initial craniectomy, primary cranioplasty, explantations, and subsequent cranioplasty to capture a holistic view of their neurosurgical history. We also collected information on patient demographics, comorbidities, underlying neurosurgical pathology, preoperative antibiotics, surgery length time, estimated blood loss (EBL), incision type, intraoperative vitals, postoperative complications, infection diagnosis and treatment, hospital length of stay, discharge destination, time between neurosurgical procedures, and mortality.

We defined cranioplasty failure as the need for explantation and surgical revision. Common indications included infection, fluid collection, bone resorption, and others. The time between the cranioplasty explantation was denoted as the time to failure. Additionally, we chose to evaluate each cranioplasty procedure separately, rather than evaluating each patient, such that if one patient underwent multiple cranioplasty procedures, each of those procedures was treated as independent of one another. If multiple procedures were performed during a single admission, the data was collected separately. Only the hospital admissions that included or involved a complication of a neurological surgery were included.

Each cranioplasty procedure was classified into one of the following three groups: 3D-printed (OssDsign $\odot ~-$ Uppsala, Sweden), autologous, and synthetic grafts (Fig. 3). The synthetic category included PEEK, titanium mesh, and PMMA implants. If a patient underwent multiple cranioplasty procedures, and if different implant materials were used for the separate procedures, then the procedure was grouped according to its respective implant category. An individual patient may have procedures separated into different groups, according to the type of implant material used.

\section{Statistical analysis}

The cranioplasty procedures were categorized into three cohorts and compared. Continuous variables were expressed as the mean \pm standard deviation, and categorical variables were expressed as a percentage or frequency.

\section{Results}

\section{Sample demographics}

In total, 60 patients underwent 71 total cranioplasty procedures. Our patient population was comprised of $40 \%$ females $(n=24)$ and $60 \%$ males $(n=40)$ with a mean age of 39.7 years (range 3-79). A majority of the subjects were Caucasian (63.3\%), with the remainder being African American (16.7\%), Hispanic (11.7\%), and Other (8.3\%). Insurance funding at the time of the cranioplasty was $45.0 \%$ private insurance, $33.3 \%$ medical assistance, and $20.0 \%$ Medicare/Medicaid. The comorbidity profile for all cohorts demonstrated a mean body mass index
(BMI) of 25.9, a $20.0 \%$ incidence of hypertension, and a 13.3\% incidence of Diabetes Mellitus Type II. Substance use was prevalent, with $53.3 \%$ of patients using alcohol, $36.7 \%$ using tobacco, and $20.0 \%$ using illicit drugs. Finally, a review of psychiatric diagnoses revealed $25.0 \%$ of subjects had depression, $18.3 \%$ had anxiety, $8.3 \%$ had Attention Deficit Hyperactivity Disorder (ADHD), and 13.3\% had a different psychiatric condition (Table 1).

\section{Craniectomy data}

The most common mechanisms of injury were blunt trauma (56.7\%), spontaneous intracranial events (ICE) (35.0\%) such as aneurysmal hemorrhage and strokes, and penetrating trauma (8.3\%). The main underlying pathology being treated with primary craniectomy was hemorrhage (63.3\%), followed by cerebral edema (20.0\%) and penetrating cerebral wounds (16.7\%).

\section{Implant data}

Of these 71 unique cranioplasty procedures, 56 (78.9\%) were a primary cranioplasty, $13(18.3 \%)$ were a secondary cranioplasty, and two (2.8\%) were a tertiary cranioplasty. Autologous bone flaps were utilized in 46 (64.8\%) of these procedures: 44 primary, two secondary, and zero tertiary. 3D flaps were used for 13 (18.3\%) procedures: six primary, six secondary, and one tertiary. Finally, synthetic flaps were used for $12(16.9 \%)$ procedures: six primary, five secondary, and one tertiary. Of these synthetic flaps, eight were titanium, three were PEEK, and one was PMMA. See Fig. 2 for CT imaging of implant cohorts.

\section{Intraoperative metrics}

The mean length of surgery for all procedures was 217.6 $( \pm$ 69.3) minutes: 224.4 $( \pm 77.3)$ minutes for autologous, $210.5( \pm 47.9)$ minutes for synthetic, and $200.8( \pm 54.3)$ minutes for 3D (Table 2). Two autologous and one synthetic outliers were removed from this analysis because they involved additional procedures (i.e. external carotidinternal carotid bypass, arteriovenous malformation resection, and tumor resection). The mean EBL for all procedures was $244.5( \pm 155.9) \mathrm{mL}: 257.6( \pm 168.6) \mathrm{mL}$ for autologous, $223.3( \pm 132.3) \mathrm{mL}$ for 3D, and $212.0( \pm 125.1)$ $\mathrm{mL}$ for synthetic. There were also two autologous outliers with EBL $>1.5 \mathrm{~L}$ excluded, as one subject underwent a bilateral cranioplasty, and the other was a pediatric subject with extensive extracranial and intracranial hemorrhage.

\section{Incision type}

For the type of surgical incision, a backwards question mark was used for 48 procedures (67.6\%), linear for eight procedures (11.3\%) T-shaped for six procedures (8.5\%), trap door for two procedures (2.8\%), and other types for seven procedures $(9.9 \%)$ (Table 2). The incisions denoted 


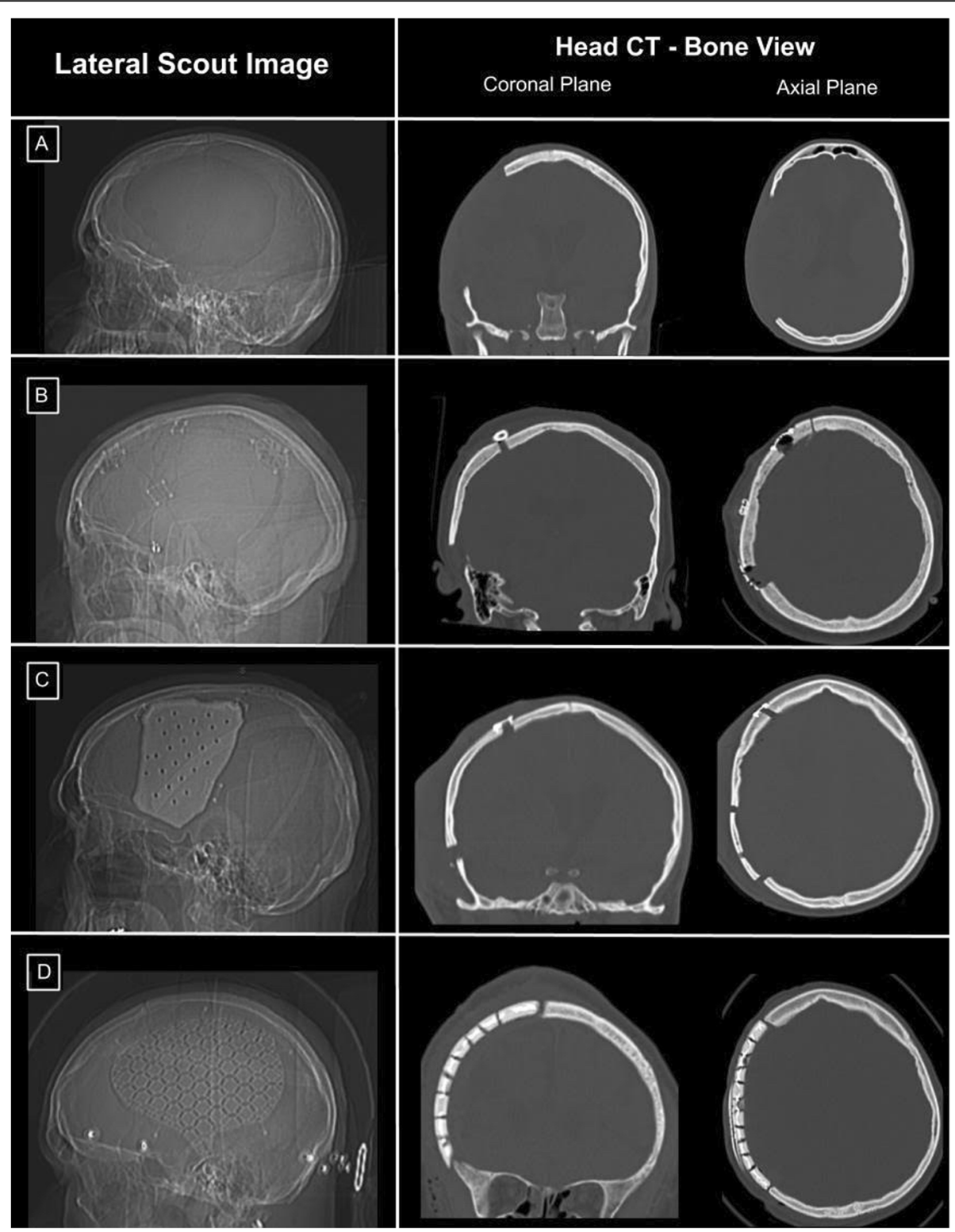

Fig. 3 Head CT Images of Autologous, Synthetic, and 3D Printed Cranioplasty Implants (a) Images of a subject post-craniectomy. (b) Images of a subject post-cranioplasty with an autologous implant. Note the defect at the inferior border of the implant in the coronal plane. (c) Images of a subject post-cranioplasty with a synthetic implant. Note the improved profile of the skull border using the synthetic implant in the coronal plane as well as the remaining inferior defect. (d) Images of a subject post-cranioplasty with a 3D printed implant. Note the improved defect repair and restoration of the native skull border profile

as "other" included horseshoe, extended lacerations, and those without details in the EMR. Of note, all autologous cranioplasties utilizing a trap-door incision failed $(n=2)$, while none of the six using a linear incision failed. Additionally, three of the 31 autologous cranioplasties using a backwards question-mark incision failed (9.7\%).

\section{Time since Craniectomy}

The mean time interval between the craniectomy or explant to the cranioplasty was 72.9 ( \pm 64.3) days overall. For the specific cohorts, the mean interval time was $47.5( \pm 41.8)$ days for autologous, $129.3( \pm$ 52.6) days for 3D, and 121.7 ( \pm 92.2) days for synthetic implants. Three outliers were removed, one from the 3D group and two from the synthetic group, due to markedly prolonged time intervals that fell more than two standard deviations away from the mean. For analysis, the remaining 68 time intervals were classified into two groups: less than 3 months, and at least 3 months. In this study, the synthetic 
Table 1 Demographic Information

\begin{tabular}{|c|c|}
\hline Characteristic & Cranioplasty \\
\hline \multicolumn{2}{|l|}{ Age } \\
\hline Mean (SD) & $39.7(17.9)$ \\
\hline Range & $3-79$ \\
\hline \multicolumn{2}{|l|}{ Sex } \\
\hline Male & $36(60 \%)$ \\
\hline Female & $24(40 \%)$ \\
\hline \multicolumn{2}{|l|}{ Race } \\
\hline African American & $10(17 \%)$ \\
\hline Caucasian & $38(63 \%)$ \\
\hline Hispanic & $7(12 \%)$ \\
\hline Other & $5(8 \%)$ \\
\hline \multicolumn{2}{|l|}{ Insurance $^{a}$} \\
\hline Medicare/Medicaid & $12(20 \%)$ \\
\hline Private Insurance & $27(45 \%)$ \\
\hline Medical Assistance & $20(33 \%)$ \\
\hline \multicolumn{2}{|l|}{ Mechanism of Injury } \\
\hline Blunt Trauma & $34(57 \%)$ \\
\hline Penetrating Trauma & $5(8 \%)$ \\
\hline Spontaneous ICE & $21(35 \%)$ \\
\hline \multicolumn{2}{|l|}{ Pathology of Injury } \\
\hline Cerebral Edema & $12(20 \%)$ \\
\hline Hemorrhage/Bleeds & $38(63 \%)$ \\
\hline Penetrating Wound & $10(17 \%)$ \\
\hline \multicolumn{2}{|l|}{ BMI } \\
\hline Mean (SD) & $25.9(5.8)$ \\
\hline \multicolumn{2}{|l|}{ Substance History } \\
\hline Alcohol & $32(53 \%)$ \\
\hline Tobacco & $22(37 \%)$ \\
\hline Illicit Drugs & $12(20 \%)$ \\
\hline \multicolumn{2}{|l|}{ Psychiatric History } \\
\hline ADHD & $5(8 \%)$ \\
\hline Anxiety & $11(18 \%)$ \\
\hline Depression & $15(25 \%)$ \\
\hline Other & $8(13 \%)$ \\
\hline \multicolumn{2}{|l|}{ Other Comorbidities } \\
\hline Diabetes Mellitus II & $8(13 \%)$ \\
\hline Hypertension & $12(20 \%)$ \\
\hline
\end{tabular}

${ }^{\mathrm{a}}$ Two patients had unknown insurance: one autologous and one synthetic $A D H D$ Attention deficit hyperactivity disorder, BMI Body mass index, ICE Intracranial event, SD Standard deviation

Small sample sizes did not allow for reliable statistical analysis

group had numerically more failures in patients whose time intervals were less than 3 months $(n=3$, $60 \%)$ compared to those of at least 3 months $(n=0$, 0\%) (Table 2).
Table 2 Descriptive Intraoperative Metrics for Cranioplasty

\begin{tabular}{|c|c|c|c|c|}
\hline & Total & $3 \mathrm{D}$ & Autologous & Synthetic \\
\hline \multicolumn{5}{|l|}{ Incision Type } \\
\hline Backwards '?' & $48(68 \%)$ & $8(17 \%)$ & $31(66 \%)$ & $9(19 \%)$ \\
\hline T-Shaped & $6(8 \%)$ & $2(33 \%)$ & $4(67 \%)$ & $0(0 \%)$ \\
\hline Linear & $8(11 \%)$ & $1(13 \%)$ & $6(75 \%)$ & $1(13 \%)$ \\
\hline Trap Door & $2(3 \%)$ & $0(0 \%)$ & $2(100 \%)$ & $0(0 \%)$ \\
\hline Other & $7(10 \%)$ & $2(29 \%)$ & $3(43 \%)$ & $2(29 \%)$ \\
\hline \multicolumn{5}{|c|}{ Surgery Length (min) } \\
\hline Mean & 217.6 & 200.8 & 224.4 & 210.5 \\
\hline SD & 69.3 & 54.3 & 77.3 & 47.9 \\
\hline \multicolumn{5}{|l|}{ EBL $(\mathrm{mL})$} \\
\hline Mean & 244.5 & 223.3 & 257.6 & 212.0 \\
\hline SD & 155.9 & 132.3 & 168.6 & 125.1 \\
\hline \multicolumn{5}{|c|}{ Time Since Craniectomy (d) } \\
\hline Mean & 72.9 & 129.3 & 47.5 & 121.7 \\
\hline SD & 64.3 & 52.6 & 41.8 & 92.2 \\
\hline
\end{tabular}

'?': Question-mark, EBL Estimated blood loss, SD Standard deviation

Small sample sizes did not allow for reliable statistical analysis

\section{Cranioplasty failure requiring reoperation}

Out of the 71 total cranioplasty procedures, 14 (19.7\%) required surgical revision (Table 3 ). These consisted of 11 primary cranioplasty failures (19.6\% failure rate), two secondary failures, and one tertiary failure. Out of the 14 total failures, nine were autologous implants (64.3\%), three were synthetic implants (21.4\%), and two were 3D implants (14.3\%). Within each category, three of the 12 total synthetic implants failed (25.0\%), nine of the 46 total autologous implants failed (19.6\%), and two of the 13 total 3D implants failed (15.4\%).

Collectively for the three groups, the average time to failure was $75.3( \pm 87.9)$ days: the autologous group was 86.4 ( \pm 94.6) days, 3D group was $29.0( \pm 8.5)$ days, and synthetic group was 80.0 ( \pm 114.14$)$ days. Of note, two autologous grafts failed at 3713 and 2310 days, both of which required interval surgical revisions that did not meet our definition of failure (i.e. removal of a single piece of hardware without cranioplasty revision). They were both excluded in this analysis.

For the failures within the autologous subgroup, four patients needed revisions due to infection, three presented with fluid collection, one experienced bone resorption, and two had other pathologies. In the $3 \mathrm{D}$ subgroup, one presented with infection and one presented with wound failure. In the synthetic subgroup, all three presented with infection (Table 3 ).

In addition, within the autologous group, the comorbid factors of tobacco use $(n=6,42.86 \%)$, and a preexisting ADHD diagnosis $(n=3,100 \%)$ were present most commonly in those that failed. 
Table 3 Cranioplasty Failure Rates

\begin{tabular}{|c|c|c|c|c|}
\hline & Total & $3 \mathrm{D}$ & Autologous & Synthetic \\
\hline \multicolumn{5}{|l|}{ Total Failures } \\
\hline Totals & 14 & 2 & 9 & 3 \\
\hline$\%$ Failed & $19.7 \%$ & $15.4 \%$ & $19.6 \%$ & $25.0 \%$ \\
\hline \multicolumn{5}{|l|}{ Primary Implant } \\
\hline Totals & 56 & 6 & 44 & 6 \\
\hline \# Failed & 11 & 1 & 8 & 2 \\
\hline$\%$ Failed & $19.6 \%$ & $16.7 \%$ & $18.2 \%$ & $33.3 \%$ \\
\hline \multicolumn{5}{|c|}{ Secondary/Tertiary Implant } \\
\hline Totals & 15 & 7 & 2 & 6 \\
\hline \# Failed & 3 & 1 & 1 & 1 \\
\hline$\%$ Failed & $20.0 \%$ & $14.3 \%$ & $50.0 \%$ & $16.7 \%$ \\
\hline \multicolumn{5}{|c|}{ Reason for Revision } \\
\hline Fluid Collection & 2 & 0 & 2 & 0 \\
\hline Infection & 8 & 1 & 4 & 3 \\
\hline Bone Resorption & 1 & 0 & 1 & 0 \\
\hline Other & 3 & 1 & 2 & 0 \\
\hline \multicolumn{5}{|l|}{ Time to Failure (d) } \\
\hline Mean & 75.3 & 29.0 & 86.4 & 80.0 \\
\hline SD & 87.9 & 8.5 & 94.6 & 114.1 \\
\hline \multicolumn{5}{|l|}{ Follow-Up Time (d) } \\
\hline Mean & 802.5 & 400.8 & 973.4 & 593.5 \\
\hline SD & 340.0 & 106.4 & 276.0 & 217.1 \\
\hline
\end{tabular}

$S D$ Standard deviation

Small sample sizes did not allow for reliable statistical analysis

\section{Discussion}

Complications from cranioplasty procedures continue to be an important issue despite the procedure's routine nature. Prior work has investigated the feasibility of utilizing 3D technology for cranioplasty implants [37-41]. A mold fabrication system has been developed that constructs cranioplasty implants with higher cranial index symmetry - matching the cranial defect more accurately - than autologous types [41-44] (Figs. 1 and 2). Other research has assessed these 3D implants using cadavers as proxies, providing insight into the efficiency of the technique and the clinical applications of employing procedures of this genre [45]. The most promising research looked retrospectively at patients undergoing calcium phosphate-based implants with 3D-printed titanium mesh reinforcement [36]. Notably, the need for explantation was found in $7.5 \%$ of these patients, who collectively had a previous failure rate of $64 \%$ in prior autologous or alloplastic implants. This study, however, did not assess the failure rates between different cranioplasty types, nor did they delve into the factors contributing to these outcomes. While the results from the present study were based on a population size that did not allow for reliable statistical testing, the raw data does provide valuable insight into the promising potential of 3D-printed implants and the elements involved in reducing cranioplasty failures.

Our study demonstrated an overall cranioplasty failure rate of $19.7 \%$ at our institution. Notably, the failure rates of synthetic implants, autologous implants, and 3D implants were $25.0 \%, 19.6 \%$, and $15.4 \%$, respectively. Infection was the leading cause of failure, with infection rates of $25.0 \%$ for synthetic, $8.7 \%$ for autologous, and $7.7 \%$ for 3D. Of note, 3D implants in this study had shorter follow-up times on average $(400.8 \pm 106.4$ days $)$ compared to the other cohorts. This may favorably bias failure rates in the 3D cohort as complications can present after a prolonged period and is noted as a limitation.

There has been a recent focus on the choice of surgical incision used and its role in cranioplasty failure. Current theories suggest that optimizing flap vascularity improves healing thus limiting infection, hardware exposure, and need for reoperation. Our study found that both of the autologous implants placed using a trap door incision, which has suboptimal vascularity, failed (100\%) compared to the backwards question mark (66\%) and linear incisions (75\%) for this cohort. This may support the hypothesis that an improved vascularity of a straighter incision may be beneficial for surgical outcomes. We also found that tobacco use was more prevalent in autologous failures (42.9\%), and that all autologous cranioplasty patients with ADHD comorbidity resulted in failures. Time from the craniectomy or explant to the cranioplasty was also a factor in synthetic failure, with those implanted in less than 3 months after craniectomy failing $60 \%$ of the time, compared to those implants at least 3 months after craniectomy having a failure rate of $0 \%$. Another intraoperative metric of note was surgery length; we found the shortest mean times for 3D implants (200.8 min), followed by synthetic $(210.5 \mathrm{~min})$ and autologous (224.4 min). While the differences in surgery lengths were not able to be statistically compared in our study due to small sample sizes, improvements in surgical efficiency and patient safety remains an important goal. The 3D-printed implants were designed precisely for this reason and to eliminate the need for manual intraoperative sculpting or reconstruction of fragmented skull pieces applied to alternative implant options (Fig. 4).

It should be noted that seven of 13 (53.8\%) 3D cases, six of $12(50.0 \%)$ synthetic cases, and two of $46(4.3 \%)$ autologous cases were revisions of at least one previously failed cranioplasty procedure. With the current standard of care favoring the use of autologous bone flaps for primary cranioplasty, this is not unexpected but does add a level of complexity to the interpretation of our data. Considering that prior failure is a major risk factor for subsequent cranioplasty failure, the $3 \mathrm{D}$ and synthetic 

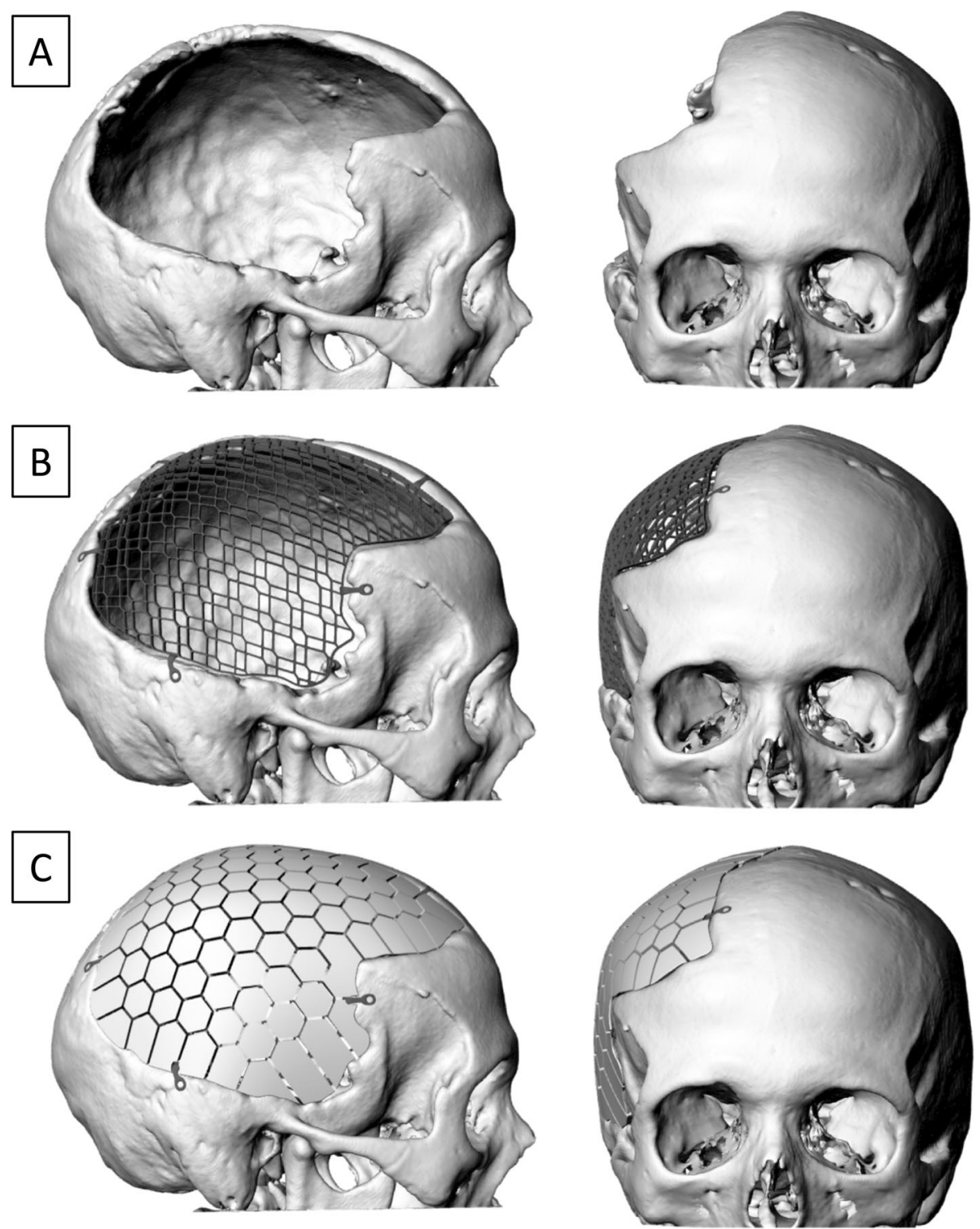

Fig. 4 Images of 3D Reconstructions of Cranial Defect and Incorporated Implant (a) Cranial defect after craniectomy. (b) Titanium skeleton with its adjustable, pre-designed fixation arms filling in the cranial defect, allowing for patient-specific customization. (c) Calcium phosphate mosaic implant integrated into the underlying titanium reinforcement

groups were already predisposed to complications. Interestingly, despite $46.2 \%$ of the $3 \mathrm{D}$ implants being utilized to replace a traditional implant that had failed, this cohort demonstrated the lowest failure rate (15.4\%). Moreover, the only $3 \mathrm{D}$ procedure to be complicated by an identified infection was in a patient who had previously undergone an autologous cranioplasty that subsequently became infected, requiring a revision with the aforementioned 3D procedure. Perhaps, given the theoretical antimicrobial and intraoperative benefits of the 3D implant, larger studies may be able to explore the potential benefit of utilizing a 3D implant as the primary material to reduce the need to surgical revision.
As with any retrospective study, the interpretation of our data carries notable limitations. The first of these is variable duration of follow-up time in the different groups. The average time to failure was 75.3 days collectively, with the longest average being 86.4 days in the autologous group, and an average follow-up time of 802.5 days across all three groups (Table 3). For those patients whose cranioplasty procedure occurred more recently, it was ensured that their charts were assessed for a minimum of 6 months following the cranioplasty, to allow enough time to observe any complications. With this consideration, it was determined that all but one procedure had follow-up times that were more than two 
standard deviations from the average time to failure. This strongly suggests that the vast majority of complications or failures that could arise from any given cranioplasty procedure were in fact observed and recorded within the timeframe of the study. Nonetheless, the longer the graft is followed, the greater the likelihood of identifying a failure.

The potential impact of confounding variables on failure rates between implant types must also be mentioned. For example, patients with a lower BMI and a preference towards optimal incision type within an implant type may skew outcomes. Another notable limitation is that due to our small sample size, we were unable to perform valid statistical analysis to determine the significance of specific factors on cranioplasty outcomes. Nonetheless, the data captured here are informative. As there are not currently any U.S. studies that compare 3D-printed implants to autologous and synthetic implants, the expansion of the present study to multiple hospitals and the inclusion of additional 3D and synthetic implants could potentially produce more robust and constructive findings. Future studies would also benefit from longer patient follow-up at various intervals, examining both minor and major complications to add more depth and detail to the findings on cranioplasty failures.

\section{Conclusion}

Based on the findings from the present study, 3Dprinted implants demonstrate potentially favorable failure rates, infection rates, and surgery times compared to autologous and synthetic implants in TBI cranial reconstruction, although statistical significance could not be determined given our limited study population. Further research on the efficacy of 3D implants and their impact on surgical outcomes using larger sample sizes and longer follow-up assessments are warranted.

\section{Abbreviations}

3D: Three-dimensional; ADHD: Attention deficit hyperactivity disorder; BMI: Body mass index; DC: Decompressive craniectomy; EBL: Estimated blood Ioss; EMR: Electronic medical records; ICE: Intracranial events; PEEK: Polyetheretherketone; PMMA: Polymethylmethacrylate; TBI: Traumatic brain injury

\section{Acknowledgments}

We thank our research staff for their assistance in data collection and data entry. We are grateful to Henrik Hjort, Ghanim Ibrahim, and Ulrik Birgersson at OssDsign (Uppsala, Sweden) for assistance in obtaining images of the 3Dprinted implants.

\section{Previous publication}

This data has not been published previously. Portions of the data were presented as an E-poster at the annual meeting for the American Association of Neurological Surgeons (AANS) in San Diego, CA which took place in April 2019.

\section{Authors' contributions}

Conceptualization: MK, DR, SM, US: Data acquisition: MK, DR, SM, GS, SK Formal analysis: MK; Interpretation of data: MK, DR, US; Validation: MK, DR,
GS; Manuscript writing and/or revision: MK, DR, US; All authors read and approved the final manuscript.

Funding

This research did not receive any specific grant from funding agencies in the public, commercial, or not-for-profit sectors.

\section{Availability of data and materials}

All data generated during the current study are available from the corresponding author on reasonable request.

\section{Ethics approval and consent to participate}

The study was approved by and conducted in full compliance with the Hennepin Healthcare Research Institute Institutional Review Board with number HSR\#17-4309.

\section{Consent for publication}

Not applicable.

\section{Competing interests}

Dr. Samadani reports receiving lecture fees from Abbott Diagnostic Laboratories, the American Association of Neuroscience Nurses, Cottage Health, Google Inc., Integra Corp, Medtronic Corp, National Neurotrauma Society; Minnesota, Texas, Louisiana and Wisconsin Coaches Associations; National Football League and USA Football; grant support from the Minnesota Department of Education (Traumatic Brain and Spinal Cord Injury): Veterans Administration, Abbott Diagnostic Laboratories, Medtronic, and Integra; having equity in Oculogica, and serving as an unaffiliated neurotrauma consultant to the National Football League for five games during each of the 2015-2018 football seasons. In regard to this present study, OssDsign was an official sponsor for a fundraising event, Charlene's Dog Run, in 2018 and 2019, which helps support Dr. Samadani's research. OssDsign was not involved in any aspect of study design, data collection, analysis, or manuscript preparation. They generously provided cranial implant design images at the authors' request, which are included in this manuscript (Figures ${ }^{* * *} \mathrm{Ok}$.

\section{Author details}

'Department of Bioinformatics and Computational Biology, University of Minnesota, 101 Pleasant Street Southeast, Minneapolis, MN 55455, USA.

${ }^{2}$ Department of Neurosurgery, Minneapolis VA Medical Center, 1 Veterans Drive, Minneapolis, MN 55417, USA.

Received: 5 February 2020 Accepted: 19 May 2020

Published online: 17 June 2020

\section{References}

1. Kolias AG, Kirkpatrick PJ, Hutchinson PJ. Decompressive craniectomy: past, present and future. Nat Rev Neurol. 2013;9:405-15. https://doi.org/10.1038/ nrneurol.2013.106.

2. Servadei F, Compagnone C, Sahuquillo J. The role of surgery in traumatic brain injury. Curr Opin Crit Care. 2007;13:163-8. https://doi.org/10.1097/mcc. Ob013e32807f2a94.

3. Stocchetti N, Maas AIR. Traumatic intracranial hypertension. N Engl J Med. 2014;370:2121-30. https://doi.org/10.1056/nejmc1407775.

4. Ashayeri K, Jackson EM, Huang J, Brem H, Gordon CR. Syndrome of the trephined: a systematic review. Neurosurgery. 2016;79:525-34. https://doi. org/10.1227/neu.0000000000001366.

5. Ban SP, Son YJ, Yang HJ, Chung YS, Lee SH, Han DH. Analysis of complications following decompressive craniectomy for traumatic brain injury. J Korean Neurosurg Soc. 2010;48:244-50. https://doi.org/10.3340/jkns.2010.48.3.244.

6. Honeybul S, Ho KM. Cranioplasty: morbidity and failure. Br J Neurosurg. 2016;30:523-8. https://doi.org/10.1080/02688697.2016.1187259.

7. Kurland DB, Khaladj-Ghom A, Stokum JA, Carusillo B, Karimy JK, Gerzanich V, et al. Complications associated with decompressive craniectomy: a systematic review. Neurocrit Care. 2015;23:292-304. https://doi.org/10.1007/ s12028-015-0144-7.

8. Bobinski L, Koskinen LOD, Lindvall P. Complications following cranioplasty using autologous bone or polymethylmethacrylate-retrospective experience from a single center. Clin Neurol Neurosurg. 2013;115:1788-91. https://doi.org/10.1016/j.clineuro.2013.04.013. 
9. Coulter IC, Pesic-Smith JD, Cato-Addison WB, Khan SA, Thompson D, Jenkins $\mathrm{AJ}$, et al. Routine but risky: a multi-Centre analysis of the outcomes of cranioplasty in the northeast of England. Acta Neurochir. 2014;156:1361-8. https://doi.org/10.1007/s00701-014-2081-1.

10. Lee $\mathrm{CH}$, Chung YS, Lee SH, Yang HJ, Son YJ. Analysis of the factors influencing bone graft infection after cranioplasty. J Trauma Acute Care Surg. 2012;73:255-60. https://doi.org/10.1097/ta.0b013e318256a150.

11. Kim H, Sung SO, Kim SJ, Kim SR, Park IS, Jo KW. Analysis of the factors affecting graft infection after cranioplasty. Acta Neurochir. 2013;155:2171-6. https://doi.org/10.1007/s00701-013-1877-8.

12. Piedra MP, Nemecek AN, Ragel BT. Timing of cranioplasty after decompressive craniectomy for trauma. Surg Neurol Int. 2014;5:25. https:// doi.org/10.4103/2152-7806.127762.

13. van de Vijfeijken SECM, Groot C, Ubbink DT, Vandertop WP, Depauw PRAM, Nout $E$, et al. Factors related to failure of autologous cranial reconstructions after decompressive craniectomy. J Cranio-Maxillofac Surg. 2019;47:1420-5. https://doi.org/10.1016/j.jcms.2019.02.007.

14. Brommeland T, Rydning PN, Pripp AH, Helseth E. Cranioplasty complications and risk factors associated with bone flap resorption. Scand J Trauma Resusc Emerg Med. 2015;23:75. https://doi.org/10.1186/s13049-015-0155-6.

15. Cabraja M, Klein M, Lehmann TN. Long-term results following titanium cranioplasty of large skull defects. Neurosurg Focus. 2009;26:e10. https://doi. org/10.3171/2009.3.focus091.

16. Cheah PP, Rosman AK, Cheang CK, Idris B. Autologous cranioplasty postoperative surgical site infection: does it matter if the bone flaps were stored and handled differently? Malays J Med Sci. 2017;24:68-74. https://doi.org/10. 21315/mjms2017.24.6.8.

17. Grant GA, Jolley M, Ellenbogen RG, Roberts TS, Gruss JR, Loeser JD. Failure of autologous bone-assisted cranioplasty following decompressive craniectomy in children and adolescents. J Neurosurg Pediatr. 2004;100: 163-8. https://doi.org/10.3171/ped.2004.100.2.0163.

18. Honeybul S, Morrison DA, Ho KM, Lind CRP, Geelhoed E. A randomized controlled trial comparing autologous cranioplasty with custom-made titanium cranioplasty. J Neurosurg. 2017;126:81-90. https://doi.org/10.3171/ 2015.12.jns152004

19. Kim SH, Kang DS, Cheong JH, Kim JH, Song KY, Kong MH. Comparison of complications following cranioplasty using a sterilized autologous bone flap or polymethyl methacrylate. Korean J Neurotrauma. 2017;13:15-23. https:// doi.org/10.13004/kjnt.2017.13.1.15.

20. Lethaus B, Bloebaum M, Essers B, ter Laak MP, Steiner T, Kessler P. Patientspecific implants compared with stored bone grafts for patients with interval cranioplasty. J Craniofac Surg. 2014;25:206-9. https://doi.org/10. 1097/scs.0000000000000396.

21. Piitulainen JM, Kauko T, Aitasalo KMJ, Vuorinen V, Vallittu PK, Posti JP. Outcomes of cranioplasty with synthetic materials and autologous bone grafts. World Neurosurg. 2015;83:708-14. https://doi.org/10.1016/j.wneu.2015.01.014.

22. Shah AM, Jung $H$, Skirboll S. Materials used in cranioplasty: a history and analysis. Neurosurg Focus. 2014;36:e19. https://doi.org/10.3171/2014.2. focus 13561.

23. Sun $Y$, Hu Y, Yuan Q, Yu J, Wu X, Du Z, et al. Association between metal hypersensitivity and implant failure in patients who underwent titanium cranioplasty. J Neurosurg. 2018;131:40-6. https://doi.org/10.3171/2018.1. jns171804.

24. Thien A, King NKK, Ang BT, Wang E, Ng I. Comparison of polyetheretherketone and titanium cranioplasty after decompressive craniectomy. World Neurosurg. 2015;83:176-80. https://doi.org/10.1016/j. wneu.2014.06.003.

25. Punchak M, Chung LK, Lagman C, Bui TT, Lazareff J, Rezzadeh K, et al. Outcomes following polyetheretherketone (PEEK) cranioplasty: systematic review and meta-analysis. J Clin Neurosci. 2017;41:30-5. https://doi.org/10. 1016/j.jocn.2017.03.028.

26. Lethaus B, Safi Y, ter Laak-Poort M, Kloss-Brandstätter A, Banki F, Robbenmenke C, et al. Cranioplasty with customized titanium and PEEK implants in a mechanical stress model. J Neurotrauma. 2012;29:1077-83. https://doi.org/10.1089/neu.2011.1794.

27. Marchac D, Greensmith A. Long-term experience with methylmethacrylate cranioplasty in craniofacial surgery. J Plast Reconstr Aesthet Surg. 2008;61: 744-52. https://doi.org/10.1016/j.bjps.2007.10.064.

28. Blum KS, Schneider SJ, Rosenthal AD. Methyl methacrylate cranioplasty in children: long-term results. PNE. 1997;26:33-5. https://doi.org/10.1159/ 000121158.
29. Matsuno A, Tanaka H, Iwamuro H, Takanashi S, Miyawaki S, Nakashima M, et al. Analyses of the factors influencing bone graft infection after delayed cranioplasty. Acta Neurochir (Wien). 2006;148:535-40. https://doi.org/10. 1007/s00701-006-0740-6.

30. de Bassumpção M, Fonoff ET, Teixeira MJ. Early resorption of an artificial bone graft made of calcium phosphate for cranioplasty: case report. Neuropsychiatr Dis Treat. 2013;9:1801-2. https://doi.org/10.2147/ndt.s43806.

31. Gilardino MS, Cabiling DS, Bartlett SP. Long-term follow-up experience with carbonated calcium phosphate cement (Norian) for cranioplasty in children and adults. Plastic Reconstr Surg. 2009;123:983-94. https://doi.org/10.1097/ prs.0b013e318199f6ad.

32. Kumar NG, Sudeep S, Balwan R. Cranioplasty of hemispherical defects using calcium phosphate cements along with titanium mesh: our experience. J Maxillofac Oral Surg. 2015;14:920-4. https://doi.org/10.1007/s12663-0150776-3.

33. van de Vijfeijken SECM, Münker TJAG, Spijker R, Karssemakers LHE, Vandertop WP, Becking AG, et al. Autologous bone is inferior to alloplastic cranioplasties: safety of autograft and allograft materials for cranioplasties, a systematic review. World Neurosurg. 2018;117:443-52.e8. https://doi.org/10. 1016/j.wneu.2018.05.193.

34. Zanaty M, Chalouhi N, Starke RM, Clark SW, Bovenzi CD, Saigh M, et al. Complications following cranioplasty: incidence and predictors in 348 cases. J Neurosurg. 2015;123:182-8. https://doi.org/10.3171/2014.9.jns14405.

35. Bonda DJ, Manjila S, Selman WR, Dean D. The recent revolution in the design and manufacture of cranial implants: modern advancements and future directions. Neurosurgery. 2015;77:814-24. https://doi.org/10.1227/neu. 0000000000000899

36. Kihlström Burenstam Linder L, Birgersson U, Lundgren K, Illies C, Engstrand T. Patient-specific titanium-reinforced calcium phosphate implant for the repair and healing of complex cranial defects. World Neurosurg. 2019;122: e399-407. https://doi.org/10.1016/j.wneu.2018.10.061.

37. Abdel Hay J, Smayra T, Moussa R. Customized polymethylmethacrylate cranioplasty implants using 3-dimensional printed polylactic acid molds: technical note with 2 illustrative cases. World Neurosurg. 2017;105:971-9.e1. https://doi.org/10.1016/j.wneu.2017.05.007.

38. Kim BJ, Hong KS, Park KJ, Park DH, Chung YG, Kang SH. Customized cranioplasty implants using three-dimensional printers and polymethylmethacrylate casting. J Korean Neurosurg Soc. 2012;52:541-6. https://doi. org/10.3340/jkns.2012.52.6.541.

39. Mobbs RJ, Coughlan M, Thompson R, Sutterlin CE, Phan K. The utility of 3D printing for surgical planning and patient-specific implant design for complex spinal pathologies: case report. J Neurosurg Spine. 2017;26:513-8. https://doi.org/10.3171/2016.9.spine16371.

40. Parthasarathy J. 3D modeling, custom implants and its future perspectives in craniofacial surgery. Ann Maxillofac Surg. 2014;4:9-18. https://doi.org/10. 4103/2231-0746.133065.

41. Tan ETW, Ling JM, Dinesh SK. The feasibility of producing patient-specific acrylic cranioplasty implants with a low-cost 3D printer. J Neurosurg. 2016; 124:1531-7. https://doi.org/10.3171/2015.5.jns15119.

42. Lim JY, Kim N, Park JC, Yoo SK, Shin DA, Shim KW. Exploring for the optimal structural design for the 3D-printing technology for cranial reconstruction: a biomechanical and histological study comparison of solid vs. porous structure. Childs Nerv Syst. 2017;33:1553-62. https://doi.org/10.1007/s00381017-3486-y.

43. Msallem B, Beiglboeck F, Honigmann P, Jaquiéry C, Thieringer F. Craniofacial reconstruction by a cost-efficient template-based process using 3D printing. Plast Reconstr Surg Glob Open. 2017;5:e158. https://doi.org/10.1097/gox. 0000000000001582.

44. Oh J. Recent advances in the reconstruction of cranio-maxillofacial defects using computer-aided design/computer-aided manufacturing. Maxillofac Plast Reconstr Surg. 2018;40:2. https://doi.org/10.1186/s40902-018-0141-9.

45. Evins Al, Dutton J, Imam SS, Dadi AO, Xu T, Cheng D, et al. On-demand intraoperative 3-dimensional printing of custom cranioplastic prostheses. Oper Neurosurg (Hagerstown). 2018;15:341-9. https://doi.org/10.1093/ons/ opx280.

\section{Publisher's Note}

Springer Nature remains neutral with regard to jurisdictional claims in published maps and institutional affiliations. 